\title{
Eastern Pacific Wind Effect on the Evolution of El Niño: Implications for ENSO Diversity
}

\author{
Qihua Peng, ${ }^{\mathrm{a}, \mathrm{b}, \mathrm{c}}$ Shang-Ping Xie, ${ }^{\mathrm{b}}$ DongXiao Wang,,${ }^{\mathrm{d}, \mathrm{e}, \mathrm{a}}$ Youichi Kamae, ${ }^{\mathrm{f}}$ Hong Zhang, ${ }^{\mathrm{g}}$ \\ Shineng Hu, ${ }^{\text {h }}$ XiaO-Tong Zheng, ${ }^{\text {i }}$ AND WeIQIANG WANG ${ }^{\mathrm{a}, \mathrm{j}}$

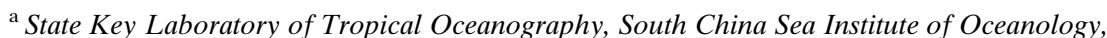 \\ Chinese Academy of Sciences, Guangzhou, China \\ ${ }^{\mathrm{b}}$ Scripps Institution of Oceanography, University of California, San Diego, La Jolla, California \\ ${ }^{\mathrm{c}}$ University of Chinese Academy of Sciences, Beijing, China \\ ${ }^{\mathrm{d}}$ Guangdong Provincial Key Laboratory of Marine Resources and Coastal Engineering, and School of \\ Marine Science, Sun Yat-sen University, Guangzhou, China \\ e Southern Marine Science and Engineering Guangdong Laboratory (Zhuhai), Zhuhai, China \\ ${ }^{\mathrm{f}}$ Faculty of Life and Environmental Sciences, University of Tsukuba, Tsukuba, Japan \\ ${ }^{\mathrm{g}}$ Joint Institute for Regional Earth System Science and Engineering, University of California, Los Angeles, \\ Los Angeles, California

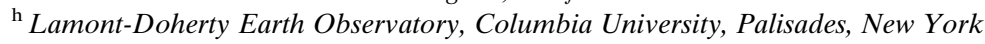 \\ i Physical Oceanography Laboratory, Ocean University of China, and Qingdao National Laboratory for \\ Marine Science and Technology, Qingdao, China \\ ${ }^{\mathrm{j}}$ Southern Marine Science and Engineering Guangdong Laboratory (Guangzhou), Guangzhou, China
}

(Manuscript received 18 June 2019, in final form 14 November 2019)

\begin{abstract}
The influence of eastern tropical Pacific $\left(\right.$ EPAC; $\left.10^{\circ} \mathrm{S}-10^{\circ} \mathrm{N}, 140^{\circ}-80^{\circ} \mathrm{W}\right)$ wind anomalies on El Niño is investigated using observations and model experiments. Extreme and moderate El Niños exhibit contrasting anomalous wind patterns in the EPAC during the peak and decay phases: westerly wind anomalies during extreme El Niño and southeasterly (southwesterly) wind anomalies south (north) of the equator during moderate El Niño. Experiments with an ocean general circulation model indicate that for extreme El Niño, the eastward intrusion of westerly wind anomalies contributes to the prolonged positive sea surface temperature (SST) anomalies in the eastern equatorial Pacific throughout boreal spring by weakened upwelling and horizontal advection. For moderate El Niño, by contrast, both the meridional and zonal anomalous winds over the EPAC are important in the rapid (slow) SST cooling south (north) of the equator through advection and wind-evaporation-SST feedback. Atmospheric model experiments confirm that these EPAC anomalous winds are primarily forced by tropical SST anomalies. The interplay between wind and SST anomalies suggests positive air-sea feedbacks over EPAC during the decay phase of El Niño. Ocean model results show that the frequency of extreme El Niño increases when EPAC wind anomalies are removed, suggesting the importance of EPAC winds for El Niño diversity.
\end{abstract}

\section{Introduction}

The El Niño-Southern Oscillation (ENSO) dominates interannual climate variability in the tropical Pacific and has global impacts of great relevance to society (e.g., Philander 1990; Clarke 2008; Sarachik and Cane 2010; Capotondi et al. 2015; Hu and Fedorov 2017). Bjerknes (1969) originally envisioned that the local weakened southeast trade winds reduce equatorial upwelling and reinforce the positive sea surface temperature anomalies

Corresponding author: Dongxiao Wang, dxwang@scsio.ac.cn
(SSTAs) over the eastern Pacific (EPAC; $10^{\circ} \mathrm{S}-10^{\circ} \mathrm{N}$, $\left.140^{\circ}-80^{\circ} \mathrm{W}\right)$. Noting that the southeast trades over EPAC change little during a typical El Niño, Wyrtki (1975) showed that the positive sea level and SSTAs over EPAC are induced by remote downwelling Kelvin waves excited near the international date line. Since then, the role of remote forcing in ENSO evolution has been studied extensively. It is now widely accepted that westerly wind anomalies in the western central Pacific are important for eastern central Pacific sea surface temperature (SST) variability (Wyrtki 1975; McCreary and Anderson 1984; Zebiak and Cane 1987). The role of 

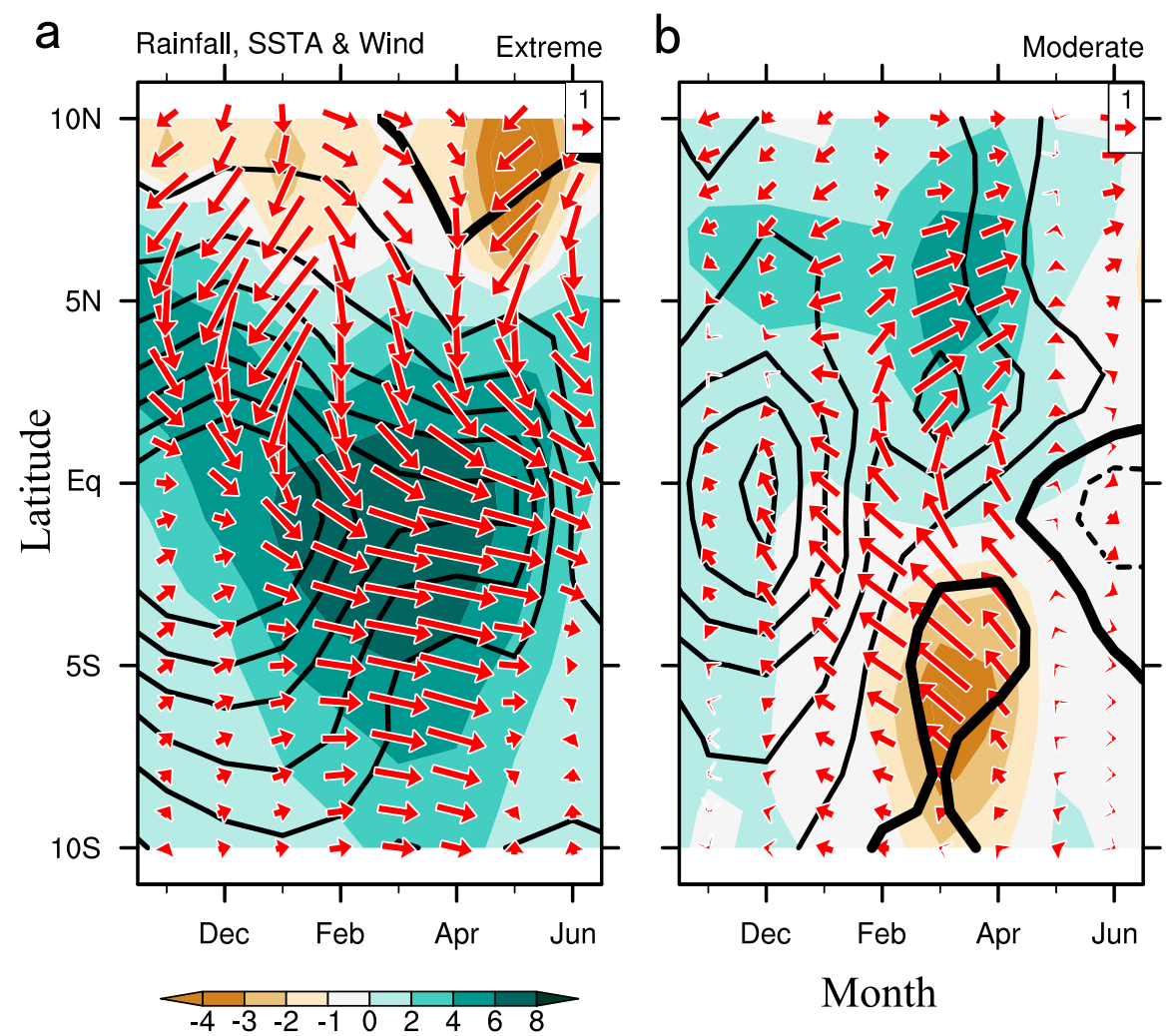

FIG. 1. Observed latitude-time evolution of (a) extreme and (b) moderate El Niños. Anomalies of precipitation ( $\mathrm{mm} \mathrm{day}^{-1}$; color shading), SST $\left({ }^{\circ} \mathrm{C}\right.$; contours at $0.2^{\circ} \mathrm{C}$ intervals; zero contour thickened), and surface wind ( $\mathrm{m} \mathrm{s}^{-1}$; vectors) are zonally averaged in $140^{\circ}-80^{\circ} \mathrm{W}$.

EPAC wind anomalies in ENSO evolution, however, receives much less attention. Some previous studies suggest that EPAC wind anomalies might be important in ENSO evolution (e.g., McPhaden 1999, 2004; Vecchi and Harrison 2006), but they tend to focus on individual El Niño events. Zhang and McPhaden (2006, 2008) systematically examined the effects of Niño-3 zonal wind stress over the full range of ENSO variability, showing that a zonal wind stress anomaly of $0.01 \mathrm{~N} \mathrm{~m}^{-2}$ leads to about $1^{\circ} \mathrm{C} \mathrm{SST}$ anomaly.

Each El Niño event is unique: ENSO events differ in spatial pattern, mechanism, and impacts. Recently, there are increasing interests in ENSO diversity (e.g., Fedorov et al. 2015; Capotondi et al. 2015; Hu and Fedorov 2018; Timmermann et al. 2018). Some authors classify ENSO events based on the SST pattern (Ashok et al. 2007; Kug et al. 2009; Kao and Yu 2009; Takahashi et al. 2011), while others emphasize the difference in rainfall anomalies (Chiodi and Harrison 2013; Cai et al. 2014; Xie et al. 2018; Okumura 2019). Here we classify ENSO into extreme and moderate types based on their rainfall patterns in the eastern tropical Pacific (Xie et al. 2018). ENSO diversity arises from multiple factors including westerly wind bursts near the date line (Hu et al. 2014;
Lian et al. 2014; Chen et al. 2015; Fedorov et al. 2015), extratropical air-sea interactions (Yu et al. 2010; Ma et al. 2017; Amaya et al. 2019), pantropical interactions (Ham et al. 2013; Cai et al. 2019), and background conditions (Yeh et al. 2009; Choi et al. 2011; McPhaden et al. 2011; Ogata et al. 2013; Okumura et al. 2017).

Different types of ENSO are characterized by contrasting wind anomaly patterns over the EPAC region (Xie et al. 2018; Lengaigne and Vecchi 2010). During an extreme El Niño, SSTs in the equatorial eastern Pacific exceed the convective threshold $\left(\sim 28^{\circ} \mathrm{C}\right.$ in the current climate; Masunaga and Kummerow 2006), and the convective anomalies can cause the anomalous westerly winds to intrude eastward into EPAC (Vecchi 2006) (Figs. 1a and 2b). These westerly wind anomalies reduce upwelling, helping the positive SSTAs in EPAC persist throughout boreal spring (Vecchi and Harrison 2006; Lengaigne and Vecchi 2010). During a moderate El Niño, the tropical eastern Pacific exhibits a different wind pattern: southeasterly (southwesterly) anomalous winds south (north) of the equator (Fig. 1b). These winds are associated with an eastern Pacific intertropical convergence zone (ITCZ) dipole (EPID) mode (Xie et al. 2018; Yu and Zhang 2018) and cause the rapid 

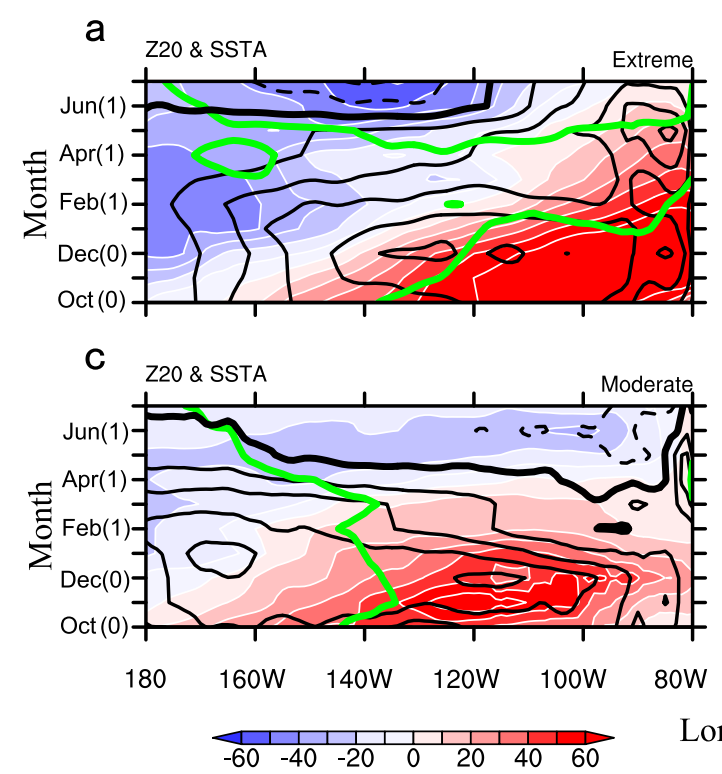

b

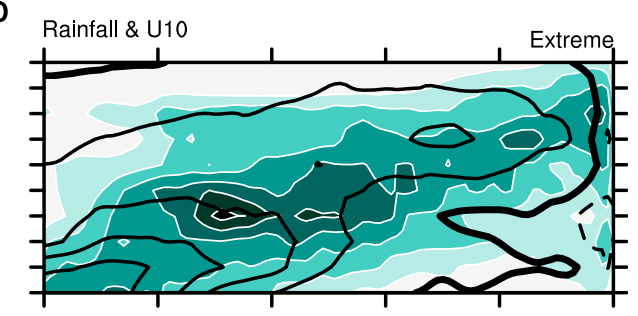

d

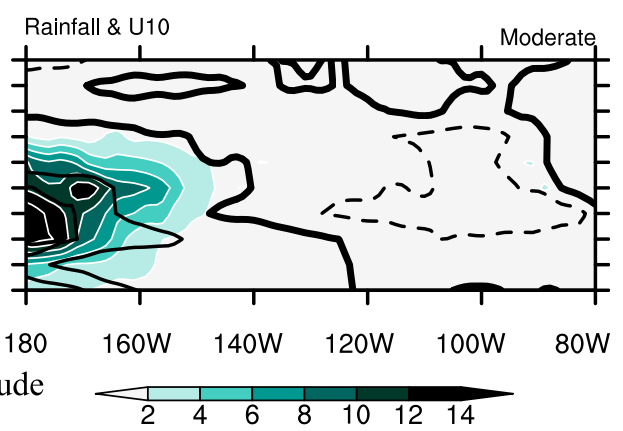

FIG. 2. Observed longitude-time evolution of (a),(b) extreme, and (c),(d) moderate El Niños. (left) $20^{\circ} \mathrm{C}$ isotherm depth anomalies ( $\mathrm{m}$, color shading), SSTA (contours at intervals of $0.5^{\circ} \mathrm{C}$, zero thickened and negative dashed), and convective threshold (green lines, $28.5^{\circ} \mathrm{C}$ in the current climate). (right) Rainfall anomalies ( $\mathrm{mm} \mathrm{day}^{-1}$, color shading), and zonal wind anomalies (contours at intervals of $0.5 \mathrm{~m} \mathrm{~s}^{-1}$, zero thickened and negative dashed). All meridionally averaged in $2^{\circ} \mathrm{S}-2^{\circ} \mathrm{N}$.

decay of moderate El Niño, thereby contributing to ENSO diversity. Nevertheless, the above hypotheses about the impacts of EPAC wind anomalies in the two types of ENSO have not yet been rigorously tested in realistic models. Important questions remain unanswered: How do EPAC wind anomalies (including zonal and meridional components) affect the extreme and moderate ENSO evolution? What are the specific oceanic mechanisms? What drives wind variability over EPAC? What are the impacts of EPAC winds on ENSO diversity?

The present study investigates these questions by using observations as well as oceanic and atmospheric general circulation models. The realistic ocean general circulation model (OGCM) enables us to quantify the EPAC wind effects on ENSO evolution and identify the relevant upper-ocean processes. We further use an atmospheric general circulation model (AGCM) to explore the causes of these EPAC anomalous winds and associated air-sea interactions. Finally, we evaluate the importance of the EPAC anomalous winds for ENSO diversity based on our OGCM and AGCM model results.

The rest of the paper is organized as follows. Section 2 describes the data and model simulations. Section 3 presents major results based on observations and OGCM simulations, that explore ocean dynamics and thermal forcing associated with EPAC wind anomalies for the two types of El Niño. Section 4 examines the causes of these local wind anomalies through AGCM experiments and discuss the associated air-sea interactions. Section 5 discusses the impacts of EPAC winds on ENSO diversity. Section 6 is a summary.

\section{Methods}

\section{a. Definition of extreme and moderate El Niños}

Due to strong nonlinearity of atmospheric convection, the traditional ENSO definition by using SST anomalies cannot capture the full range of atmospheric variability related to ENSO. Here we define the extreme and moderate El Niños from an atmospheric convective view following Xie et al. (2018). Specifically, empirical orthogonal function (EOF) analysis is performed on February-April (FMA) rainfall anomalies over the eastern tropical Pacific. The leading EOF mode, featuring large rainfall anomalies over the eastern equatorial Pacific and high correlation $(r=0.74)$ between PC1 and Niño-3 SST, captures extreme El Niño events with intensified deep convection (Figs. 2a and 2b of Xie et al. 2018). The extreme El Niño events of 1982/83 and 1997/98 stand out, with PC1 for FMA eastern Pacific precipitation above two standard deviations.

The second EOF mode, characterized by a meridional rainfall dipole mode over the eastern tropical Pacific and 
high correlation $(r=0.64)$ between PC2 and Niño-4 SSTAs, is associated with moderate ENSO (Figs. 2c and $2 \mathrm{~d}$ of Xie et al. 2018). PC2 exceeds 0.5 standard deviations in moderate El Niño events of $1987 / 88$, 1991/92, 1994/95, 2002/03, 2004/05, and 2009/10; and falls below -0.5 standard deviations in La Niña events of 1984/85, 1985/86, 1988/89, 1999/2000, 2005/06, 2008/09, and 2016/17. Detailed information about the definition can be found in Xie et al. (2018). This definition of extreme and moderate ENSO provides new insights in understanding ENSO diversity because they account for the nonlinear, threshold-like response of deep convection to SST.

It should be noted that the 2015/16 El Niño is one of the strongest events by the metric of November-January (NDJ) Niño-3.4 index. Compared to the extreme El Niño events of 1982/83 and 1997/98, the largest SST anomalies during the 2015/16 event are displaced westward with distinct mechanisms and impacts (Paek et al. 2017). Indeed, the $2015 / 16 \mathrm{El} \mathrm{Niño} \mathrm{is} \mathrm{a} \mathrm{mixture} \mathrm{of} \mathrm{extreme}$ and moderate ENSO (Xie et al. 2018; Timmermann et al. 2018), characterized by moderately positive PC1 and PC2 values (Xie et al. 2018).

\section{b. Observational data}

We analyze the observational data to explore the spatiotemporal evolution of El Niño events. We employ the NOAA Optimum Interpolation Sea Surface Temperature version 2 dataset (OISST; https://www.esrl.noaa.gov/psd/ data/gridded/data.noaa.oisst.v2.html) at $1^{\circ} \times 1^{\circ}$ resolution during 1982-2017 (Reynolds et al. 2002); the 10-m wind velocity from the European Reanalysis (ERA) Interim (http://apps.ecmwf.int/datasets/data/interimfull-daily/levtype $=\mathrm{sfc} /$ ) on a $1^{\circ} \times 1^{\circ}$ grid (Dee et al. 2011) during 1979-2017; the Climate Prediction Center (CPC) Merged Analysis of Precipitation (CMAP; https://www.esrl. noaa.gov/psd/data/gridded/data.cmap.html) (Xie and Arkin 1997) dataset during $1979-2017$ on a $2.5^{\circ} \times 2.5^{\circ}$ grid. In addition, we use the NCEP Global Ocean Data Assimilation System (GODAS; https://www.esrl.noaa.gov/psd/data/ gridded/data.godas.html) data to characterize the evolution of the thermocline depth, as represented by the $20^{\circ} \mathrm{C}$ isotherm depth.

\section{c. Model experiments}

\section{1) $\mathrm{OGCM}$}

The OGCM utilized in this study is the MIT General Circulation Model (MITgcm) (Marshall et al. 1997). The model resolution is $1^{\circ}$ in the zonal direction and $0.3^{\circ}$ in the meridional direction near the equator, stretching to $1^{\circ}$ at midlatitudes. The model has 50 layers in the vertical direction. Restarting from an initial state obtained from Estimating the Circulation and Climate of the Ocean, version 4 Release 3 (ECCO v4r3; Forget et al. 2015; Fukumori et al. 2017), the MITgcm was integrated forward in time from 1 January 1979 to 31 December 2017, with 6-hourly forcing fields from the European Centre for MediumRange Weather Forecasts (ECMWF) interim reanalysis (ERA-Interim) products (Dee et al. 2011). The surface latent heat (LH) and sensible heat (SH) fluxes are calculated online using a bulk formula. To separate the impacts of dynamic processes and thermal forcing [notably wind-evaporation-SST (WES) feedback; Xie and Philander 1994], wind stress and wind speed variability are imposed separately in the model. More information about the model configuration and forcing fields can be found in Peng et al. (2019).

To evaluate the effects of EPAC wind anomalies on the evolution of extreme/moderate El Niño, we have performed four experiments (Table 1). The control run (CTL) is forced with full forcing for 1979-2017 and contains the complete processes of ENSO. From CTL, we construct composites of extreme (CTLEXT) and moderate (CTLMOD) El Niño events. The no zonal wind stress run $\left(\mathrm{No} \tau_{x}^{\prime}\right)$ is initialized from the CTL hindcast for each El Niño and La Niña but keeps EPAC zonal wind stress fixed to the monthly climatological value during September (0)-August (1) [Here numerals in the parentheses denote the El Niño develop (0) and decay (1) year]. Extreme (No $\tau_{x}^{\prime}$ EXT) and moderate (No $\left.\tau_{x}^{\prime} \mathrm{MOD}\right)$ El Niño composites are then obtained from these no zonal wind stress experiments. The difference, CTL $-\mathrm{No} \tau_{x}^{\prime}$, thus isolates the effects of EPAC zonal wind stress anomalies on extreme (CTLEXT -No $\tau_{x}^{\prime}$ EXT) and moderate (CTLMOD $\left.-\mathrm{No} \tau_{x}^{\prime} \mathrm{MOD}\right)$ ENSO. The changes of EPAC wind stress in these experiments may give rise to unintended wind stress curl forcing off the equator. To reduce these impacts of unintended wind stress curl, we set up a $5^{\circ}$ transition zone where zonal wind stress forcing outside the EPAC gradually changes to the realistic forcing fields.

Similarly, in the no meridional wind stress $\left(\mathrm{No} \tau_{y}^{\prime}\right)$ and no wind speed runs (NoWspeed), EPAC meridional wind stress and wind speed are fixed to monthly climatological values in the EPAC region. The resultant composites denote the overall effects excluding the meridional wind stress and wind speed anomalies, respectively. The difference, CTL - No $\tau_{y}^{\prime}$, implies the dynamical effects of meridional wind stress on extreme (CTLEXT - No $\tau_{y}^{\prime}$ EXT) and moderate (CTLMOD No $\tau_{y}^{\prime}$ MOD) ENSO, while CTL - NoWspeed represents the EPAC wind speed variability effects on extreme 
TABLE 1. Description of the MITgcm experiments.

\begin{tabular}{|c|c|c|}
\hline Experiments & Forcing & Description \\
\hline CTL & $\begin{array}{l}\text { Full forcing. Extreme (CTLEXT) and moderate } \\
\text { (CTLMOD) El Niño composites are then } \\
\text { obtained by the hindcast run. }\end{array}$ & All processes included. \\
\hline $\mathrm{No} \tau_{x}^{\prime}$ & $\begin{array}{l}\text { Same as CTL but using monthly climatological } \\
\text { zonal wind stress in EPAC during September } \\
(0)-\text { August }(1) \text { for each El Niño. Extreme } \\
\left(\text { No } \tau_{x}^{\prime} \text { EXT) and moderate (No } \tau_{x}^{\prime} \mathrm{MOD}\right) \mathrm{El} \\
\text { Niño composites are then obtained by these } \\
\text { experiments. }\end{array}$ & $\begin{array}{l}\mathrm{CTL}-\mathrm{No} \tau_{x}^{\prime} \text { isolates the EPAC zonal wind stress variability } \\
\text { effects on extreme (CTLEXT - No } \tau_{x}^{\prime} \text { EXT) and } \\
\left.\text { moderate (CTLMOD - No } \tau_{x}^{\prime} \mathrm{MOD}\right) \text { El Niño. }\end{array}$ \\
\hline $\mathrm{No} \tau_{y}^{\prime}$ & $\begin{array}{l}\text { Same as No } \tau_{x}^{\prime} \text { but using monthly climatological } \\
\text { meridional wind stress over EPAC region. }\end{array}$ & $\begin{array}{l}\mathrm{CTL}-\mathrm{No} \tau_{y}^{\prime} \text { represents the EPAC meridional wind stress } \\
\left.\text { variability effects on extreme (CTLEXT - No } \tau_{y}^{\prime} \mathrm{EXT}\right) \\
\text { and moderate }\left(\mathrm{CTLMOD}-\mathrm{No} \tau_{y}^{\prime} \mathrm{MOD}\right) \text { El Niño. }\end{array}$ \\
\hline NoWspeed & $\begin{array}{l}\text { Same as No } \tau_{x}^{\prime} \text { but using monthly climatological } \\
\text { wind speed over EPAC region. }\end{array}$ & $\begin{array}{l}\text { CTL - NoWspeed isolates the impacts of EPAC wind speed } \\
\text { anomalies on extreme (CTLEXT - NoWspeedEXT) and } \\
\text { moderate (CTLMOD - NoWspeedEXT) El Niño. }\end{array}$ \\
\hline
\end{tabular}

(CTLEXT - NoWspeedEXT) and moderate ENSO (CTLMOD - NoWspeedMOD).

\section{2) AGCM}

We use the Community Atmosphere Model version 5.3 (CAM5.3), developed at the National Center for Atmospheric Research (NCAR). It is released as the atmosphere component of the Community Earth System Model version 1.2.2 (CESM1.2.2; Neale et al. 2012). The model resolution is $0.9^{\circ}$ latitude $\times 1.25^{\circ}$ longitude ("f09_f09") with 30 sigma levels in the vertical.

To measure the atmospheric response to the tropical SST pattern of extreme and moderate El Niño, we conduct three main sets of experiments, titled "ACTL," "AEXT," and "AMOD." In the control run (ACTL, Table 2), the model is forced by the monthly climatology of SST and sea ice during 1980-2017 from the Hadley Centre Global Sea Ice and Sea Surface Temperature (HadISST). In the AEXT run, an extreme El Niño composite of SSTAs, which evolves from September (0) of the El Niño developing year to August (1) of the decay year, is added only in the tropical Pacific region $\left(10^{\circ} \mathrm{S}-10^{\circ} \mathrm{N}, 140^{\circ} \mathrm{E}-80^{\circ} \mathrm{W}\right.$, with $5^{\circ}$ linear tapering zones outside this region) to force the AGCM. The difference solution, AEXT - ACTL, thus denotes the atmospheric response of extreme El Niño SSTAs. Similarly, in AMOD (Table 2), we impose September (0)-August (1) moderate ENSO composite of SSTAs only in the tropical Pacific region $\left(10^{\circ} \mathrm{S}-10^{\circ} \mathrm{N}, 140^{\circ} \mathrm{E}-80^{\circ} \mathrm{W}\right)$. The difference solution, AMOD - ACTL, is used to investigate the impacts of moderate ENSO SSTAs on the atmosphere. Each run lasts for 11 years and the results of the last 10 years are analyzed.

\section{d. A mixed layer heat budget}

To better understand the mechanisms of how EPAC winds affect ENSO decay, we conducted a mixed layer heat budget analysis for the two types of El Niño composites in the OGCM experiments. The heat-budget equation (Kang et al. 2001) is

$$
\begin{aligned}
T_{t}^{\prime}= & -\left[\left(u^{\prime} T_{x}+\bar{u} T_{x}^{\prime}+u^{\prime} T_{x}^{\prime}\right)+\left(v^{\prime} \bar{T}_{y}+\bar{v} T_{y}^{\prime}+v^{\prime} T_{y}^{\prime}\right)\right. \\
& \left.+\left(w^{\prime} \bar{T}_{z}+\bar{w} T_{z}^{\prime}+w^{\prime} T_{z}^{\prime}\right)\right]+Q^{\prime}+R
\end{aligned}
$$

where the overbars and primes indicate monthly climatology and anomaly, respectively. Variables $u, v$, and $T$ indicate zonal current, meridional current, and oceanic temperature, respectively, averaged over the mixed layer. Vertical velocity $(w)$ is calculated at the bottom of the mixed layer. The $Q^{\prime}$ is the surface heat flux term and $R$ is the residual term. Here $Q^{\prime}$ is calculated by

\begin{tabular}{|c|c|}
\hline Experiment & Forcing \\
\hline ACTL & $\begin{array}{l}\text { Forced by the monthly climatological SST } \\
\text { obtained from HadISST }\end{array}$ \\
\hline AEXT & $\begin{array}{l}\text { Extreme El Niño composite of SSTAs } \\
\text { over the tropical Pacific region } \\
\left(10^{\circ} \mathrm{S}-10^{\circ} \mathrm{N}, 140^{\circ} \mathrm{E}-80^{\circ} \mathrm{W} \text {, with } 5^{\circ} \text { linear }\right. \\
\text { tapering zones outside this region) } \\
\text { during September (0) to August (1) is } \\
\text { added to the climatological SST. }\end{array}$ \\
\hline AMOD & $\begin{array}{l}\text { Same as AEXT but moderate ENSO } \\
\text { composite of SSTAs is added to the } \\
\text { climatological SST. }\end{array}$ \\
\hline
\end{tabular}

TABLE 2. Description of the CAM experiments. 


$$
Q^{\prime}=\frac{Q_{\mathrm{net}}^{\prime}-Q_{\mathrm{pen}}^{\prime}}{\rho c_{P} h},
$$

where $h$ is the climatological mixed layer depth, and $Q_{\text {net }}^{\prime}$ represents the net surface heat flux. The $Q_{\text {pen }}^{\prime}$ is the shortwave radiation transmitted through the bottom of the mixed layer depth, which is parameterized (Paulson and Simpson 1977) as follows:

$$
Q_{\text {pen }}^{\prime}=Q_{\text {short }}^{\prime}\left(0.58 e^{-h / 0.35}+0.42 e^{-h / 23}\right),
$$

where $Q_{\text {short }}^{\prime}$ is the shortwave heat flux at the sea surface. The residual term $(R)$ represents all remaining unresolved processes, notably the vertical mixing.

For the extreme El Niño, we focus on the mechanism that maintains positive SSTAs in the eastern equatorial Pacific throughout the decay phase. Thus, we construct extreme El Niño composites from OGCM, and then compute each term in the heat budget equation in the eastern equatorial region $\left(2^{\circ} \mathrm{S}-2^{\circ} \mathrm{N}, 120^{\circ}-80^{\circ} \mathrm{W}\right)$. For the moderate El Niño, we are interested in the mechanism underlying the cross-equator asymmetric SSTAs. We compute the heat budget in two boxes: the northern box $\left(0^{\circ}-5^{\circ} \mathrm{N}, 120^{\circ}-80^{\circ} \mathrm{W}\right)$ and the southern box $\left(0^{\circ}-5^{\circ} \mathrm{S}, 120^{\circ}-80^{\circ} \mathrm{W}\right)$. Their difference indicates the contribution of each term to the crossequatorial asymmetric SSTAs.

\section{Impacts of EPAC winds on ENSO evolution}

Figure 3a shows that the simulated Niño-3 index agrees well with observations $(r=0.95)$, suggesting that the model can capture the interannual SST variability in the eastern Pacific. Before proceeding into detailed analysis, it is also necessary to validate the simulated SSTA evolution of CTLEXT and CTLMOD. Figure 3 compares Hovmöller diagrams of equatorial SSTA between observation and the simulation. The model reproduces many features of the observed SST evolution that are the focus of this work (Fig. 3). For instance, the positive SSTAs of simulated extreme El Niño peak in November-January (NDJ), persist into boreal spring, and terminate in boreal summer, much as in observations (Figs. 3b,d). The simulated SSTAs of moderate El Niño also peak in NDJ but decay rapidly in boreal spring. Moderate El Niño SSTAs develop strong asymmetry across the equator, which is also evident in observations (Figs. 3c,e). Overall, the good model/observation agreement suggests that this configuration of MITgcm is able to capture the fundamental processes governing the decay phase of the two types of El Niño and thus is suitable for our investigation.

\section{a. Extreme El Niño}

During the peak and decay phases of extreme El Niño, the tropical eastern Pacific is characterized by strong positive SSTAs near the equator and strong northwesterly wind anomalies in EPAC (Fig. 1a). To isolate the impacts of zonal and meridional EPAC wind anomalies, No $\tau_{x}^{\prime}$, No $\tau_{y}^{\prime}$, and NoWspeed experiments are performed. Effects of zonal/meridional wind stress and wind speed anomalies are assessed by CTLEXT $-\mathrm{No} \tau_{x}^{\prime}$ EXT, CTLEXT - No $\tau_{y}^{\prime}$ EXT, and CTLEXT - NoWspeedEXT, respectively (section $2 \mathrm{c}$ and Table 1 ).

In the CTLEXT composite, large positive SSTAs $\left(\sim 3^{\circ} \mathrm{C}\right)$ in EPAC persist throughout boreal spring and vanish by July (1)-August (1) (Fig. 4a). Without the EPAC wind anomalies, however, positive SSTAs decay rapidly and vanish during April (1)-May (1), implying that EPAC wind anomalies play a crucial role in sustaining the warm SST throughout the decay phase of extreme El Niño (Fig. 4e). Note that SSTAs of CTLEXT - No $\tau_{x}^{\prime}$ EXT (Figs. 4b and 5b) are much larger than those of CTLEXT - No $\tau_{\mathrm{y}}^{\prime}$ EXT (Figs. 4c and 5c) and CTLEXT - NoWspeedEXT (Figs. 4d and 5d), indicating that the EPAC zonal wind stress anomalies dominate the slow decay process of extreme El Niño and the impacts of meridional wind anomalies and wind speed anomalies are negligible (Figs. 5c,d). Hence, hereafter we focus on the effect of zonal wind stress.

We conduct a heat budget analysis for the mixed layer temperature averaged in the eastern equatorial Pacific region $\left(2^{\circ} \mathrm{S}-2^{\circ} \mathrm{N}, 120^{\circ}-80^{\circ} \mathrm{W}\right)$. Figure $5 \mathrm{e}$ shows that the horizontal and vertical advection terms are important positive contributors to the SST warming during February (1)-June (1). The zonal advection is dominated by the term $-u^{\prime} \bar{T}_{x}$ (Fig. 5e). The intruding westerly anomalous winds drive strong anomalous eastward currents (Figs. 4b and 5b), transporting climatological warm water toward the eastern equatorial Pacific (Fig. 5a) and raising mixed layer temperature there. The meridional advection is dominated by the term, $-v^{\prime} \bar{T}_{y}$. Indeed, the westerly wind anomalies drive anomalous equatorward currents in the Ekman layer, transporting climatological warm water from higher latitudes to the cold tongue region (Figs. 5a,b) and then increasing SST there. In addition, the $-\bar{v} T_{y}^{\prime}$ term also contributes to the persistent warming.

The vertical terms play a crucial role in sustaining the warm SST throughout the decay of extreme El Niño. It is dominated by two terms: $-w^{\prime} \bar{T}_{z}$ and $-\bar{w} T_{z}^{\prime}$. Specifically, the anomalous downwelling currents in the equatorial region (Figs. 4b and 5b) lead to large positive values of $-w^{\prime} \bar{T}_{z}$. On the other hand, the zonal wind anomalies can affect the thermocline feedback term $\left(-\bar{w} T_{z}^{\prime}\right)$ by 

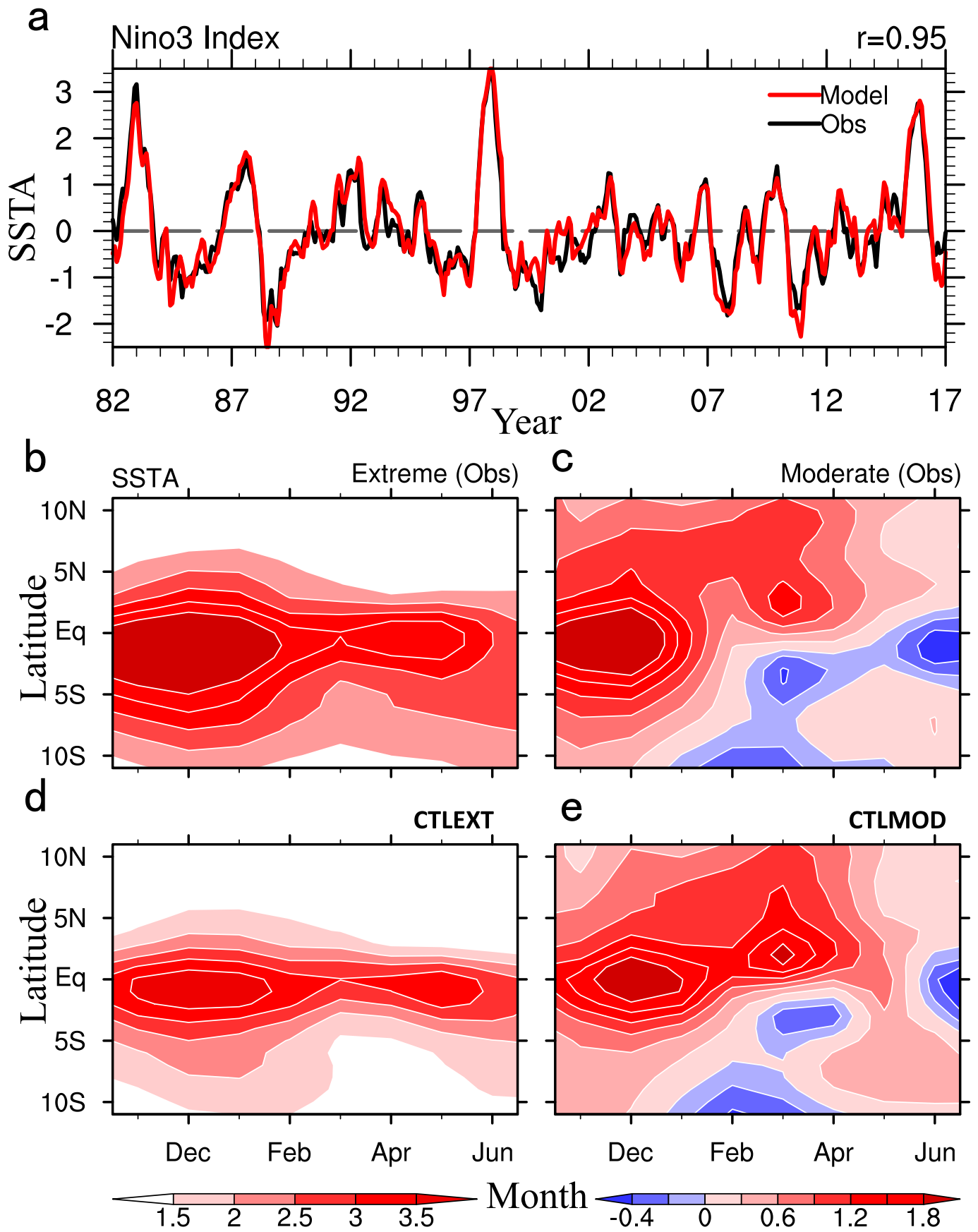

FIG. 3. Comparison of observed and modeled SSTAs. (a) Time series of observed (black line) and simulated (red line) Niño-3 index. Hovmöller diagrams of observed SSTAs for (b) extreme and (c) moderate El Niño. (d),(e) As in (b),(c), but for the simulated SSTAs for CTLEXT and CTLMOD, respectively. All zonally averaged in $120^{\circ}-80^{\circ} \mathrm{W}$. The correlation $(r)$ between observed and simulated Niño-3 indices is statistically significant at the $95 \%$ confidence level based on $t$ test.

deepening the thermocline and hence changing the vertical stratification.

Taken together, both the horizontal and vertical advection terms are important for the persistence of mixed layer temperature during the decay process of extreme
El Niño. Previous studies have emphasized that the westerly wind anomalies drive anomalous downwelling currents, which then warm the eastern Pacific SSTs through vertical advection (Lengaigne and Vecchi 2010; Xie et al. 2018). Our model results verify this hypothesis 


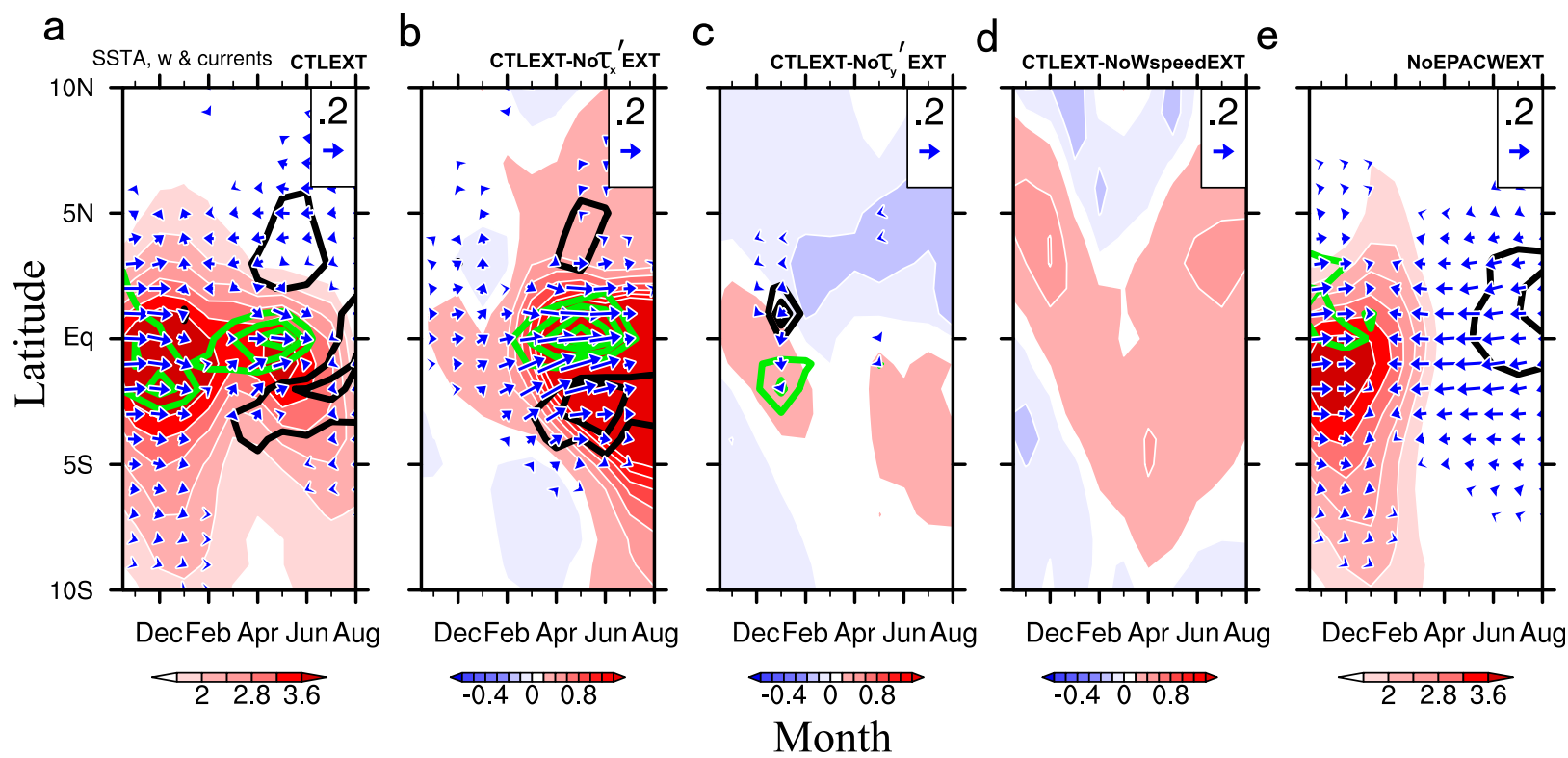

FIG. 4. Simulated latitude-time evolution of extreme El Niño. Hovmöller diagrams of (a) SSTA (color shading; ${ }^{\circ} \mathrm{C}$ ), vertical velocity at the base of the mixed layer (contours with an interval of $3.0 \times 10^{-6} \mathrm{~m} \mathrm{~s}^{-1}$; zero contour omitted, positive contours in black and negative contours in green), and mixed layer current anomalies (vectors; $\mathrm{m} \mathrm{s}^{-1}$ ) of CTLEXT; (b)-(d) as in (a), but for the effect of EPAC zonal wind stress anomalies (CTLEXT - No $\tau_{x}^{\prime}$ EXT), meridional wind stress anomalies (CTLEXT - No $\tau_{x}^{\prime}$ EXT), and wind speed anomalies (CTLEXT - NoWspeedEXT), respectively. (e) As in (a), but for the results of no EPAC wind anomalies (NoEPACW) during extreme El Niño (NoEPACWEXT), which is obtained by (a)-(d). All zonally averaged in $120^{\circ}-80^{\circ} \mathrm{W}$.

and further reveal that the horizontal advection terms and thermocline feedback term are also important in sustaining the positive eastern Pacific SSTAs throughout the decay phase.

\section{b. Moderate El Niño}

In contrast to extreme El Niño, moderate El Niño features southeasterly (southwesterly) wind anomalies in the tropical southeastern (northeastern) Pacific during the peak and decay phases (Fig. 1b). In the CTLMOD composite, SSTAs in EPAC exhibit strong asymmetry across the equator: negative south of the equator and weakly positive north of the equator (Fig. 6a). Figure 6e shows that the cross-equatorial SSTA asymmetry vanishes without the EPAC wind anomalies. Instead, SSTAs are much more persistent and symmetric about the equator in the eastern equatorial Pacific, implying that EPAC wind anomalies are important in the evolution of moderate El Niño. Specifically, zonal wind stress anomalies play a crucial role in terminating the SST warming near the equator $\left(2^{\circ} \mathrm{S}-2^{\circ} \mathrm{N}\right)$ (Zhang and McPhaden 2008) and inducing asymmetric SSTAs outside the equatorial region $\left(2^{\circ}-7^{\circ} \mathrm{N}\right.$ and $\left.2^{\circ}-7^{\circ} \mathrm{S}\right)$ (Figs. $6 \mathrm{~b}$ and $7 \mathrm{~b}$ ). The meridional wind stress anomalies cool SST south of the equator and raise SST north of the equator, acting as a positive contributor to the SST asymmetry (Figs. 6c and $7 \mathrm{c}$ ). In addition, the strengthened (weakened) wind speed anomalies south (north) of the equator decrease (increase) SST south (north) of the equator, also contributing to the SST asymmetry across the equator (Figs. 6d and 7d).

To further examine the detailed physical process underlying the cross-equatorial asymmetric SSTAs, heat budget analysis is applied separately to the northern $\left(0^{\circ}-5^{\circ} \mathrm{N}, 120^{\circ}-80^{\circ} \mathrm{W}\right)$ and southern $\left(0^{\circ}-5^{\circ} \mathrm{S}, 120^{\circ}-\right.$ $80^{\circ} \mathrm{W}$ ) boxes during February (1)-April (1). The heat budget difference between these two boxes thus denotes the impacts of each term on the asymmetric SSTAs. The southerly wind anomalies contribute to the meridional asymmetry of SSTAs due to the vertical and zonal advection terms (Fig. 7e). The vertical term is dominated by $-w^{\prime} \bar{T}_{z}$ : as the Coriolis effect vanishes on the equator, the southerly anomalous winds drive a shallow overturning cell across the equator (Philander and Pacanowski 1981), decreasing SST south of the equator through intensified oceanic upwelling and increasing SST north of the equator through weakened upwelling (Fig. 7c; Xie et al. 2018; Peng et al. 2019). The zonal advection term is dominated by $-u^{\prime} \bar{T}_{x}$. Specifically, the southerly wind anomalies drive anomalous westward Ekman currents south of the equator (Figs. 6c and 7c), transporting climatological cold water outside the southeastern Pacific (Figs. 7a,c) and decreasing SST there. However, north of the equator, the southerly wind anomalies forced 

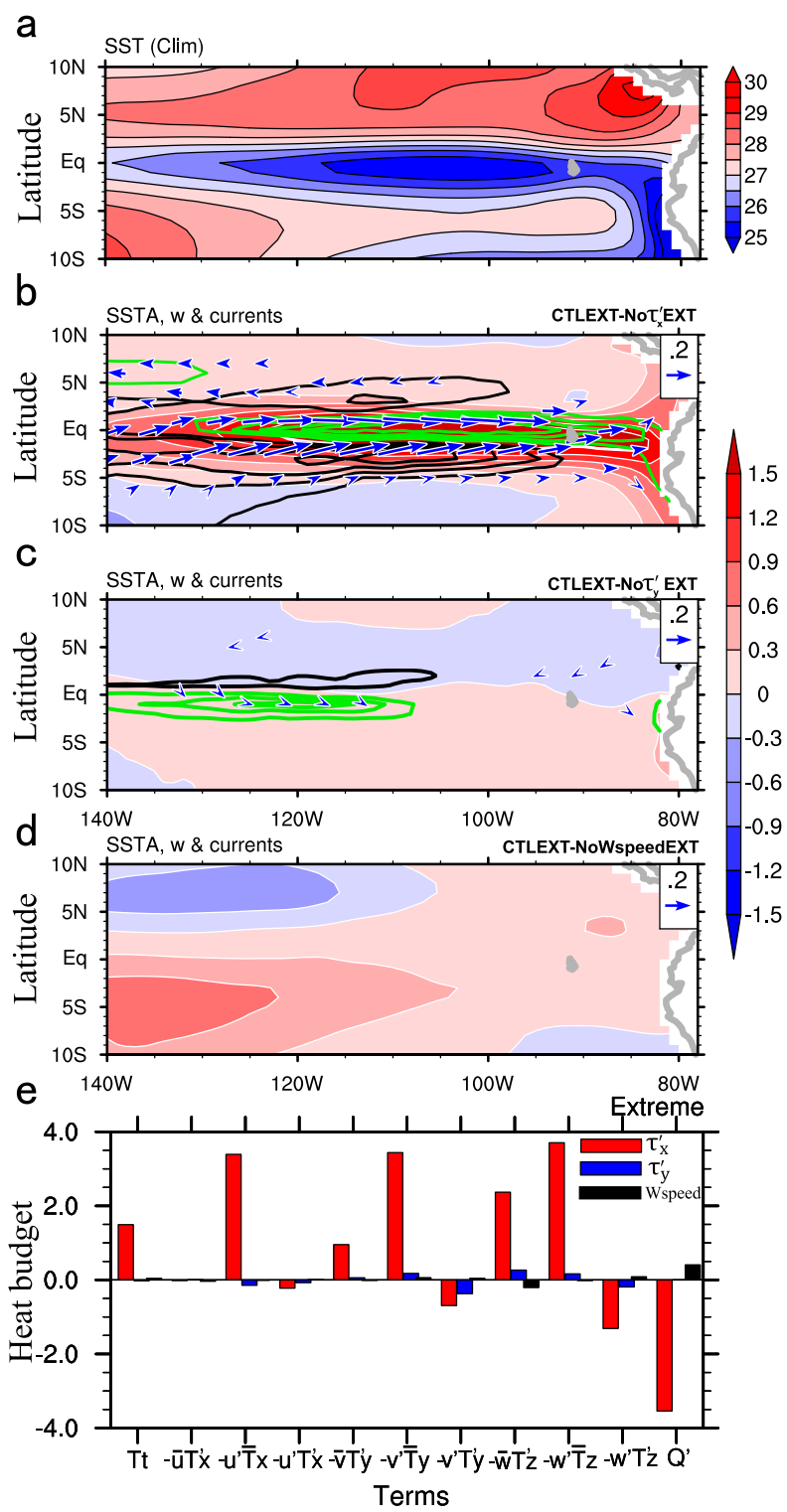

FIG. 5. February-June mean oceanic anomalies of extreme El Niño. (a) Climatological SST $\left({ }^{\circ} \mathrm{C}\right.$; color shading) from the hindcast run of the MITgcm. Anomalies of SST $\left({ }^{\circ} \mathrm{C}\right.$; color shading), vertical velocity at the bottom of mixed layer $\left(w ; \mathrm{m} \mathrm{s}^{-1}\right.$; contours with an interval of $2.0 \times 10^{-6} \mathrm{~m} \mathrm{~s}^{-1}$; zero contour omitted positive contours in black and negative contours in green), and mixed layer currents $\left(\mathrm{m} \mathrm{s}^{-1}\right.$; vectors) induced by EPAC (b) zonal (CTLEXT - No $\tau_{x}^{\prime}$ EXT) and (c) meridional wind stress anomalies (CTLEXT - No $\left.\tau_{\mathrm{y}}^{\prime} \mathrm{EXT}\right)$ and (d) wind speed anomalies (CTLEXT - NoWspeedEXT), respectively. (e) Mixed layer heat budget terms $\left(10^{-7}{ }^{\circ} \mathrm{Cs}^{-1}\right)$ due to variability in EPAC zonal and meridional wind stress as well as wind speed. All the heat budget terms averaged in $2^{\circ} \mathrm{S}-2^{\circ} \mathrm{N}, 120^{\circ}-80^{\circ} \mathrm{W}$.

Ekman currents are eastward, leading to positive values of $-u^{\prime} \bar{T}_{x}$ and increasing SST there.

The EPAC zonal wind stress anomalies play a crucial role in the cross-equatorial asymmetric SSTAs (Fig. 7b). The term $-v^{\prime} \bar{T}_{y}$ dominates the heat budget (Fig. 7e).
During the decay of moderate El Niño, easterly (westerly) wind anomalies south (north) of the equator (Fig. 1b) drive anomalous Ekman southward currents. North (South) of the equator, these anomalous southward currents carry climatological warm (cold) water from northeastern tropical Pacific (cold tongue) to the cold tongue (southeastern Pacific) (Figs. 7a,b), increasing (decreasing) SST there. Thus, the anomalous southward currents contribute to the asymmetric SSTAs through the $-v^{\prime} \bar{T}_{y}$ term. In addition, the zonal advection term $\left(-u^{\prime} \bar{T}_{x}\right)$ also contribute to the meridional asymmetry of SSTAs but it is much smaller than the $-v^{\prime} \bar{T}_{y}$ term. Taken together, the zonal wind anomalies amplify the cross-equatorial asymmetric SSTAs, and cause Niño-3 SST to cool overall. From an atmospheric dynamic perspective, the cross-equatorial variations in zonal wind off the equator (easterly wind anomalies south of the equator and westerly wind anomalies north of the equator; Fig. 1b) result from the cross-equatorial meridional wind through the Coriolis force (Chang and Philander 1994). To our knowledge, this indirect effect of meridional wind anomalies through zonal wind anomalies on SST asymmetry has not been previously discussed in the literature.

The wind speed is also important for the rapid decay of SSTAs in the southeastern tropical Pacific (Figs. 6d and $7 \mathrm{~d}$ ). South of the equator, the anomalous winds, notably the anomalous southerly winds, accelerate the southeast trade winds (Fig. 1), increasing wind speed and lowering SST with enhanced surface evaporation. This WES feedback (Xie and Philander 1994) induces sizable cooling $\left(\sim 1^{\circ} \mathrm{C}\right)$ south of the equator (Figs. $6 \mathrm{~d}$ and $7 \mathrm{~d}$ ) and hence amplifies the meridional asymmetry of SSTAs (Fig. 7e).

Therefore, we conclude that the meridional and resultant zonal wind stress anomalies as well as wind speed contribute to the meridional asymmetry of SSTAs through horizontal advection, vertical advection and WES feedback. Xie et al. (2018) highlighted the effect of anomalous meridional winds and WES feedback, and our model results further reveal that the zonal wind anomalies, which are the result of the anomalous meridional winds through the Coriolis force, are also important for the asymmetric SSTAs.

\section{Causes of EPAC wind anomalies and associated air-sea interactions}

\section{a. Extreme El Niño}

It is clear now that westerly wind anomalies over EPAC are important for the persistence of positive SSTAs in the decay of extreme El Niño. To further explore the causes of these anomalous westerly winds, we performed two AGCM experiments (section 2c and Table 2). Figure 8 a presents the $10-y r$ mean 

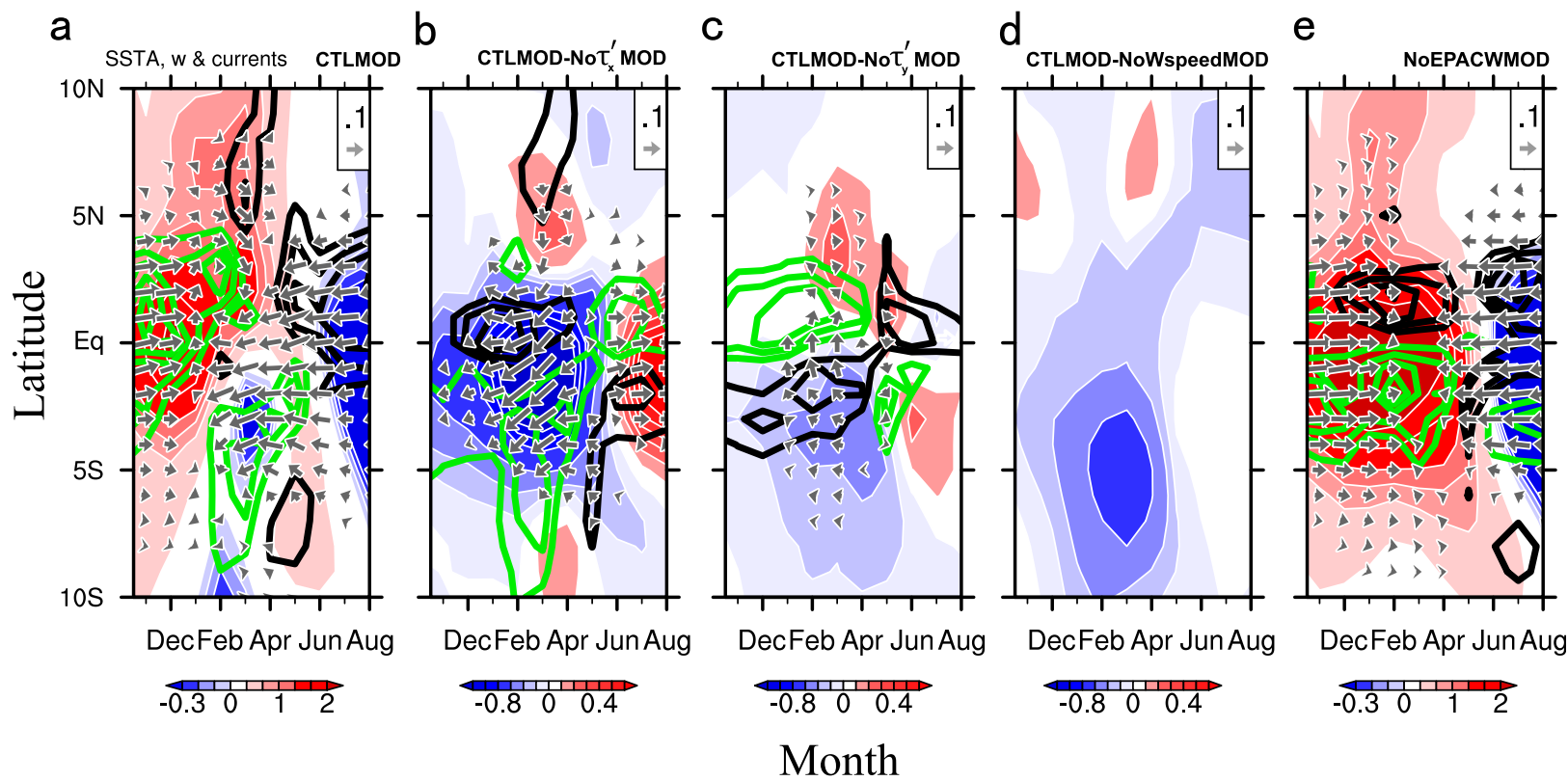

FIG. 6. As in Fig. 4, but for moderate El Niño. The contour interval is $1.0 \times 10^{-6} \mathrm{~m} \mathrm{~s}^{-1}$. All zonally averaged in February-April (FMA).

precipitation and surface wind anomalies over the eastern Pacific from the AEXT run. The evolution and spatial pattern of precipitation and wind anomalies from AEXT run compare well with observations (Fig. 1a), indicating that rainfall and wind anomalies are forced by tropical Pacific SSTAs. Indeed, deep convection is important in driving these westerlies. During extreme El Niño, large positive SSTAs drive the eastern equatorial Pacific to exceed the convective threshold, causing deep convection and heavy rainfall there. This drives westerly wind anomalies to intrude into the eastern equatorial Pacific (Chiodi and Harrison 2013; Johnson and Kosaka 2016).

As mentioned above, the intrusion of the westerly wind anomalies further increases SST in the eastern equatorial Pacific. Taken together, these results suggest strong air-sea interactions over the EPAC in the evolution of extreme El Niño. This local EPAC Bjerknes feedback plays a vital role in the evolution of extreme El Niño throughout the peak and decay phases, characterized by the eastward copropagation of SST, rainfall, and westerly wind anomalies (Figs. 2a,b).

\section{b. Moderate El Niño}

Likewise, we conduct an additional experiment (named AMOD) by imposing the moderate El Niño SSTAs pattern over the tropical Pacific. The difference, AMOD - ACTL, denotes the impacts of moderate El Niño SSTAs on the rainfall and wind anomalies (see section $2 \mathrm{c}$ and Table 2). Figure $8 \mathrm{~b}$ shows that the simulated atmospheric response during the decay phase of moderate El Niño closely resembles the observations, indicating the anomalous southeasterly (southwesterly) winds south (north) of the equator are mainly forced by tropical SSTAs. It should be noted that the observed southwesterly wind anomalies north of the equator (Fig. 1) are stronger than the simulation (Fig. 8). Such a discrepancy could be due to the forcing outside the tropical Pacific [e.g., the tropical North Atlantic warming; $\mathrm{Hu}$ and Fedorov (2018)]. Figure $8 b$ shows that in NDJ, SSTAs are to first order symmetric about the equator. However, the climatological mean SST is strongly asymmetric over the eastern Pacific, above the convective threshold only north of the equator (Fig. 7a). So deep convection is intensified only north of the equator, driving anomalous southerly cross-equatorial winds. Outside the equator, these southerly wind anomalies generate easterly (westerly) wind anomalies south (north) of the equator (Fig. 1b) through the Coriolis force. In addition, the southerly wind anomalies drive northward surface currents on the equator where the Coriolis effect vanishes, with intensified upwelling and decreased SST to the south (Philander and Pacanowski 1981; Xie et al. 2018). The southeastern Pacific SST cooling (Figs. 2c and 9f) further produces a sea level pressure gradient that generates the low-level easterly wind anomalies (Dewitte and Takahashi 2019). The cross-equatorial southerly wind anomalies along with the resultant easterly wind anomalies contribute to the rapid termination of moderate El Niño. 


\section{a}
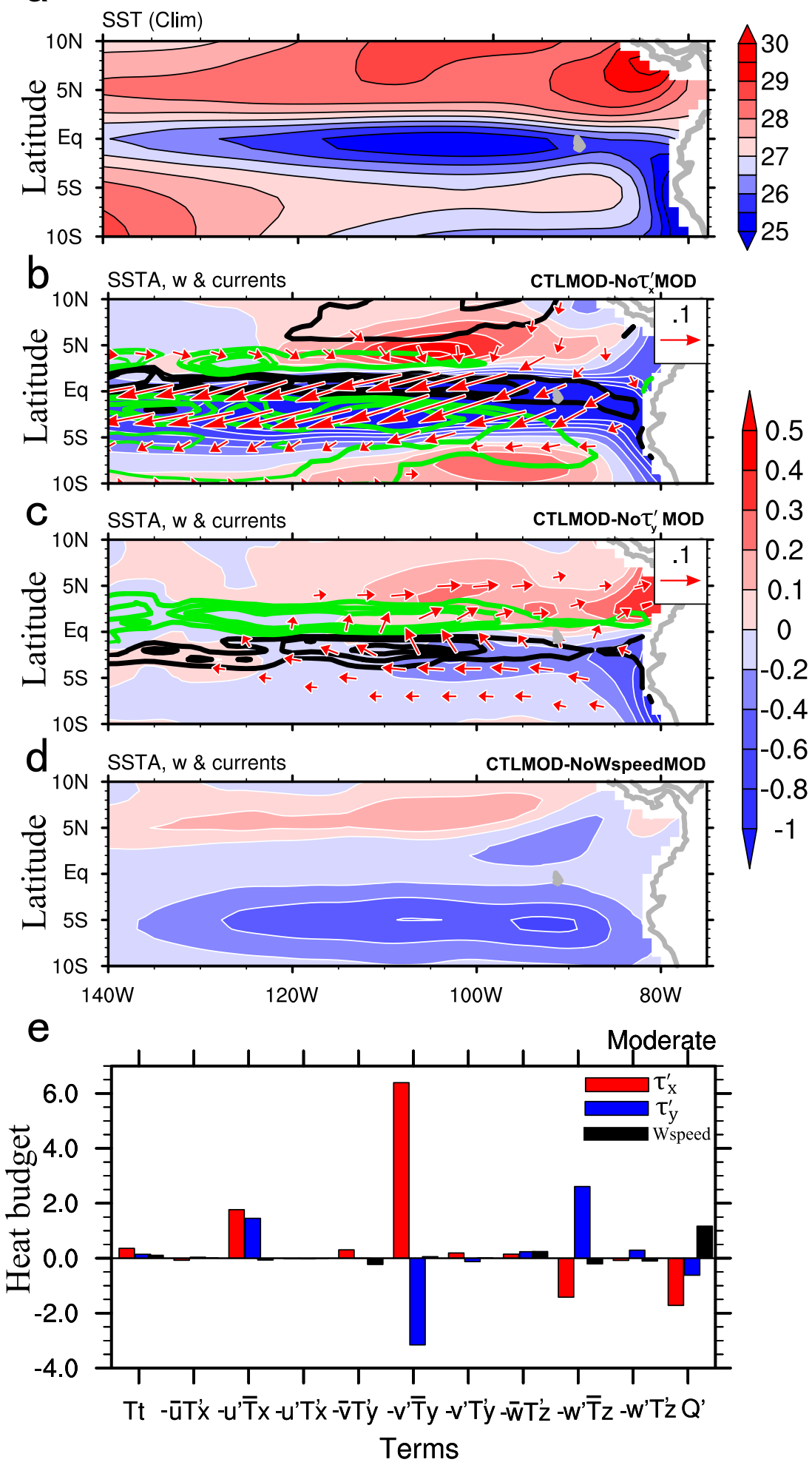

FIG. 7. As in Fig. 5, but for moderate El Niño. The vertical velocity contours are with an interval of $1.0 \times 10^{-6} \mathrm{~m} \mathrm{~s}^{-1}$. (e) The cross-equatorial difference in mixed layer budget terms $\left(10^{-7}{ }^{\circ} \mathrm{C} \mathrm{s}^{-1}\right)$ between $0^{\circ}-5^{\circ} \mathrm{N}$ and $0^{\circ}-5^{\circ} \mathrm{S}$ (zonally averaged in $\left.120^{\circ}-80^{\circ} \mathrm{W}\right)$. All averaged in FMA. 


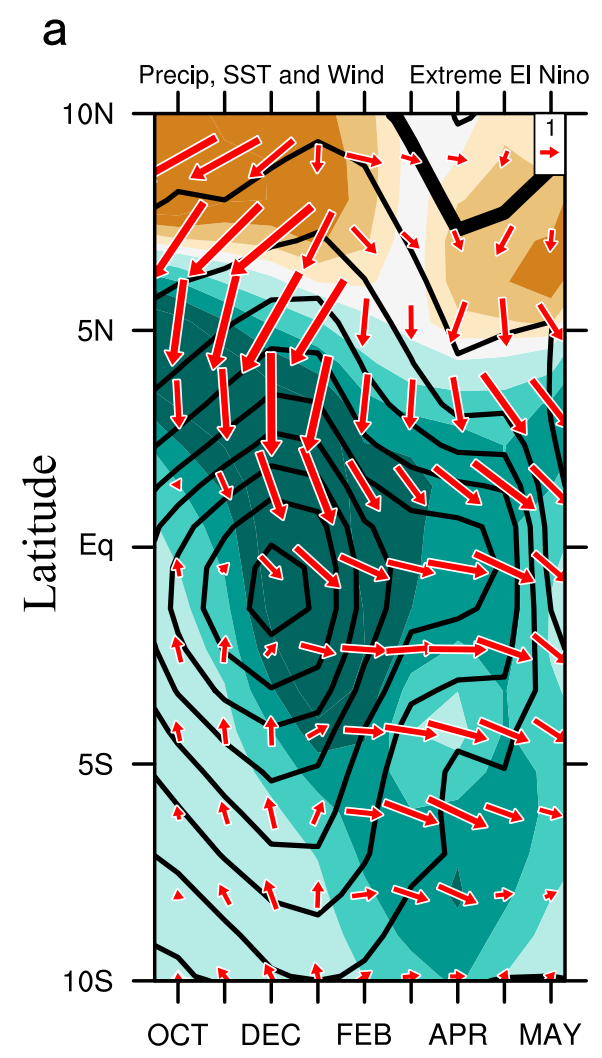

b

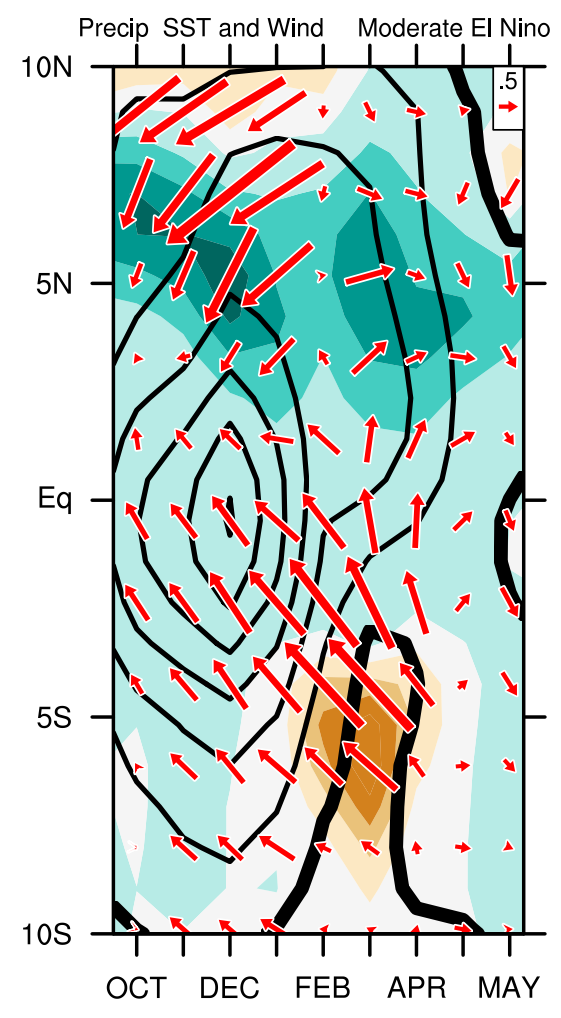

Month

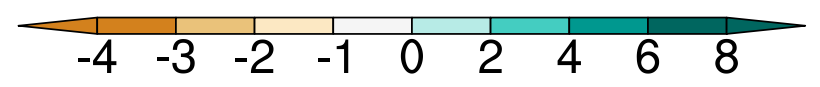

FIG. 8. Evolution of (a) extreme (AEXT - ACTL), and (b) moderate El Niño (AMOD - ACTL) from the AGCM. Anomalies of precipitation ( $\mathrm{mm} \mathrm{day}^{-1}$; color shading), SSTA $\left({ }^{\circ} \mathrm{C}\right.$; contours at $0.2^{\circ} \mathrm{C}$ intervals; zero contour thickened), and surface wind ( $\mathrm{m} \mathrm{s}^{-1}$; vectors). All zonally averaged in $140^{\circ}-80^{\circ} \mathrm{W}$.

The anomalous winds over EPAC increase SST north of the equator whereas they decrease SST south of the equator through oceanic dynamics (Figs. 6b,c) and WES feedback (Fig. 6d). The cross-equatorial SSTA asymmetry can further enhance the anomalous winds. This air-sea interaction then evolves into an antisymmetric EPID mode (Xie et al. 2018) in FMA season, which is very important in the rapid decay of moderate El Niño.

\section{Discussion}

During El Niño events, positive SSTAs over EPAC can be amplified by local Bjerknes feedback. Typically, only strong warm events (as in 1983 and 1998) cause deep convection in the eastern equatorial Pacific (Fig. 10a) and drive westerly wind anomalies to intrude into this region (Figs. 1a and 2b). The EPAC westerly wind anomalies deepen the thermocline (Fig. 9e), drive anomalous eastward ocean currents and weaken upwelling there
(Figs. 4b and 5b), helping sustain SSTAs of the extreme El Niño. During February-May, climatological Niño-3 SSTs reach the annual maximum (Fig. 10a, gray line). SSTAs of the extreme El Niño drive EPAC above the convective threshold (Fig. 10a, black line). The local Bjerknes feedback amplifies the warm event, with pronounced influences on global weather and climate (Siler et al. 2017).

For warm events of moderate amplitudes, by contrast, eastern equatorial SSTs are not high enough to trigger deep convection (Figs. 10b and 2d), and the deep convection anomalies are confined to the north of the equator, driving cross-equatorial southerly wind anomalies (Fig. 1b). These anomalous southerlies accelerate (decelerate) the southeast (northeast) trade winds south (north) of the equator through the Coriolis effect, limiting the growth of SST warming through advection and thermocline feedback. Specifically, the southeasterly wind anomalies over the equatorial Pacific drive westward ocean currents and intensify upwelling near 
a
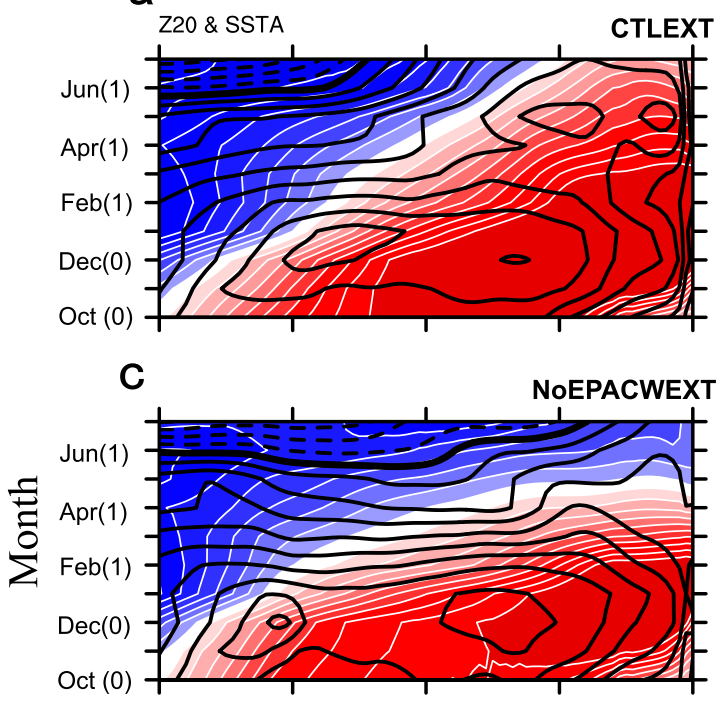

e

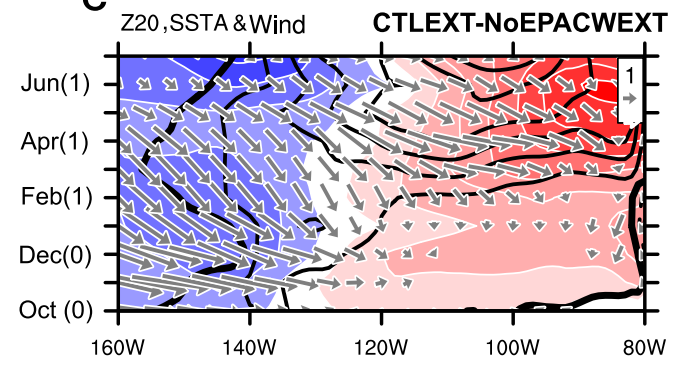

b

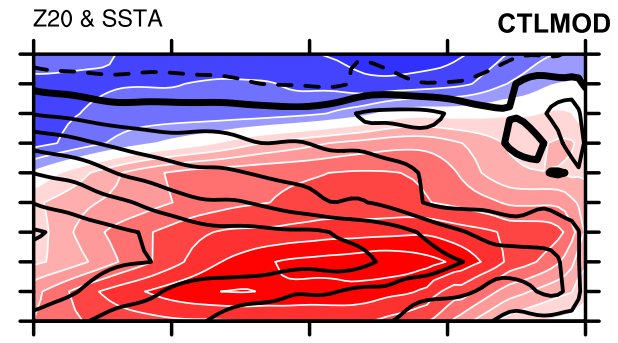

d

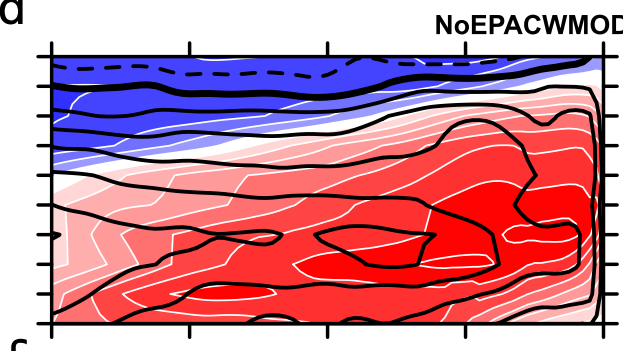

$f$
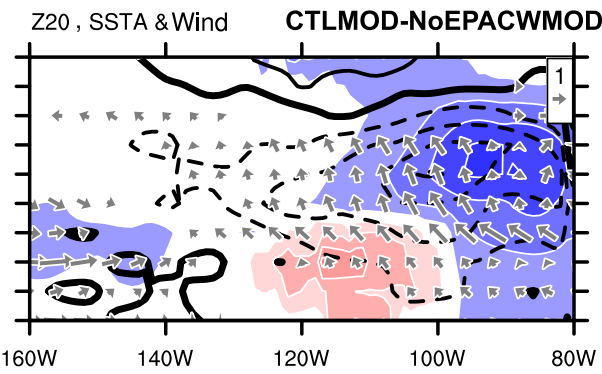

Longitude

$-50-40-30-20-10 \quad 0 \quad 1020 \quad 3040 \quad 50$

FIG. 9. Longitude-time evolution of $20^{\circ} \mathrm{C}$ isotherm depth anomalies ( $\mathrm{m}$, color shading), and SSTA (contours at intervals of $0.5^{\circ} \mathrm{C}$, zero contour thickened and negative contours dashed) for (a) CTLEXT and (b) CTLMOD. (c),(d) As in (a),(b), but for the results without EPAC wind anomalies during extreme (NoEPACWEXT) and moderate (NoEPACWMOD) El Niño. (e),(f) The total EPAC wind effect, calculated as the upper minus middle panel difference. Vectors in (e) and (f) denote wind anomalies $\left(\mathrm{m} \mathrm{s}^{-1}\right)$. All meridionally averaged in $2^{\circ} \mathrm{S}-2^{\circ} \mathrm{N}$.

the equator (Figs. $6 \mathrm{~b}$ and $7 \mathrm{~b}$ ), lowering SST through horizontal and vertical advection. In addition, the EPAC wind anomalies shoal the thermocline over the eastern equatorial Pacific (Fig. 9f). As a consequence, positive thermocline depth anomalies induced by the central Pacific westerly wind anomalies are damped before arriving at the South American coast (Fig. 9c), and the thermocline feedback is thus unimportant for moderate El Niño (Kug et al. 2009; Kao and Yu 2009). Without EPAC wind variability, however, positive thermocline depth anomalies propagate into the eastern Pacific, resulting in amplified, eastward copropagating SSTAs (Figs. 9d,f). Thus, the thermocline feedback could become important if EPAC wind variability is suppressed. Indeed, without the EPAC wind anomalies, SSTs in the Niño-3 region rise above the convective threshold in boreal spring (Fig. 10b, dotted black line), which would activate the Bjerknes feedback over the EPAC region. Taken together, these results indicate that a moderate El Niño can potentially grow into an extreme El Niño but the EPAC cross-equatorial southerly wind pattern (Fig. 1b) limits the growth of moderate El Niño, thereby reducing the occurrence of extreme El Niño.

The southeast cross-equatorial winds in the eastern Pacific strengthened since the 1980s (Hu and Fedorov 2018), with decreased SSTs over the south equatorial Pacific. The colder mean state makes it harder for SST over the eastern equatorial Pacific to pass the convective threshold, implying that it is more difficult for the ITCZ to migrate onto the equator. As a result, the eastern Pacific preferentially selects the cross-equatorial southerly wind pattern (Fig. 1b) during El Niño. This may explain why no extreme El Niño with strong EPAC convection has occurred over the past two decades. During the peak phase of 


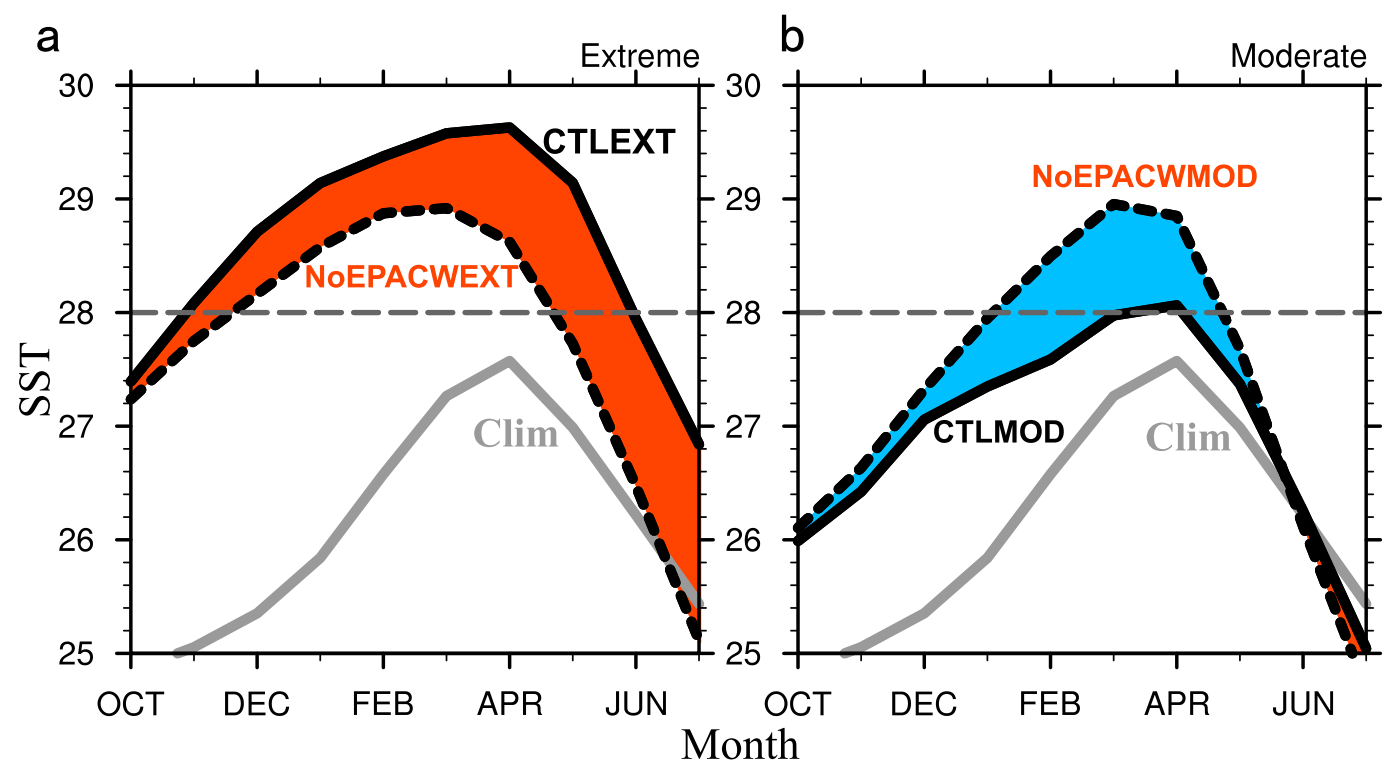

FIG. 10. (a) Evolution of eastern equatorial Pacific SST with the full wind forcing (CTLEXT, black line) and without EPAC wind anomalies (NoEPACWEXT, dotted black line) for extreme El Niño. The climatology is plotted in gray as the reference. The SST difference between CTLEXT and NoEPACWEXT is filled with colors (positive in red and negative in blue). (b) As in (a), but for moderate El Niño. All averaged in $5^{\circ} \mathrm{S}-5^{\circ} \mathrm{N}, 140^{\circ}-80^{\circ} \mathrm{W}$.

the 2015-16 El Niño, for example, large SSTAs are observed in the central and eastern equatorial Pacific but the multidecadal intensification of the southerlies keeps the ITCZ north of the equator (Hu and Fedorov 2018), inhibiting the EPAC Bjerknes feedback and preventing this El Niño from growing into an extreme El Niño. Further investigation into the relationship between the decadal wind change and extreme El Niño is underway.

\section{Conclusions}

We have investigated the impacts and causes of EPAC wind anomalies during extreme and moderate El Niño by using ocean and atmospheric GCMs. Observed extreme and moderate El Niños exhibit distinct EPAC wind anomalies especially during the decay phase. Our model results show that the EPAC wind anomalies play a key role in the distinct evolution between two types of El Niño through distinct mechanisms and airsea interactions.

At the peak phase of extreme El Niño, SSTAs are high enough to trigger deep convection in the equatorial eastern Pacific, driving the westerly wind anomalies to intrude into the eastern Pacific (Fig. 9). These local EPAC anomalous westerlies then reduce equatorial upwelling and drive warm water to the cold tongue through horizontal advection, increasing eastern Pacific SSTs. This local EPAC Bjerknes feedback sustains the positive SSTAs throughout late spring to early summer.
For moderate El Niño, eastern equatorial Pacific SSTAs are not high enough for deep convection. In NDJ, symmetric SSTAs of a moderate El Niño induce an asymmetric atmospheric response as a result of the asymmetric mean state, driving anomalous crossequatorial southerly winds and inducing an easterly (westerly) wind component south (north) of the equator through the Coriolis effect. These wind anomalies decrease (increase) the SST in the southeastern (northeastern) equatorial Pacific through enhanced (weakened) upwelling, horizontal advection and WES feedback (Xie et al. 2018). The asymmetric SSTAs further enhance the wind anomalies.

Our results reveal that the EPAC wind pattern is important in affecting ENSO type. Specifically, the intrusion of westerly wind anomalies in EPAC (Fig. 1a) amplifies the SST warming for an extreme El Niño while southeasterly (southwesterly) anomalous winds south (north) of the equator (Fig. 1b) inhibit SST warming and are more likely to result in a moderate El Niño. While we here focus on the EPAC wind variability effects during peak and decay phases of ENSO. A range of other factors also affect ENSO diversity, such as westerly wind bursts near the date line (e.g., Chen et al. 2015; Fedorov et al. 2015), pantropical interactions (e.g., Ham et al. 2013; Cai et al. 2019), extratropical air-sea interactions (e.g., Ma et al. 2017; Amaya et al. 2019), and decadal changes in the background state (e.g., Yeh et al. 2009; Okumura et al. 2017). These potential factors 
often work together to affect ENSO diversity. For instance, strong westerly wind bursts near the date line typically excite extreme El Niño through the downwelling Kelvin waves and thermocline feedback (e.g., the $1983 / 83$ and $1997 / 98$ events), but this relationship can be interrupted by the EPAC wind anomalies. The acceleration of cross-equatorial southeasterly winds over the EPAC can inhibit EPAC Bjerknes feedback and prevent the El Niño from growing into extreme magnitude (e.g., the 2015/16 case). More research is needed to study the relative importance and interconnections of these factors.

Acknowledgments. This work is supported by the National Natural Science Foundation of China (41521005), the National Key Research and Development Program of China (2016YFC1401702), the Key Special Project for Introduced Talents Team of Southern Marine Science and Engineering Guangdong Laboratory (Guangzhou) (GML2019ZD0306), the China Scholarship Council (201604910798), and the Independent Research Project Program of State Key Laboratory of Tropical Oceanography (LTOZZ1802). S.P.X. is supported by the U.S. National Science Foundation (1637450). The numerical simulation is supported by the High Performance Computing Division and HPC managers of Wei Zhou and Dandan Sui in the South China Sea Institute of Oceanology.

\section{REFERENCES}

Amaya, D. J., Y. Kosaka, W. Zhou, Y. Zhang, S.-P. Xie, and A. J. Miller, 2019: The North Pacific pacemaker effect on historical ENSO and its mechanisms. J. Climate, 32, 7643-7661, https:// doi.org/10.1175/JCLI-D-19-0040.1.

Ashok, K., S. K. Behera, S. A. Rao, H. Weng, and T. Yamagata, 2007: El Niño Modoki and its possible teleconnection. J. Geophys. Res., 112, C11007, https://doi.org/10.1029/2006JC003798.

Bjerknes, J., 1969: Atmospheric teleconnections from the equatorial Pacific. Mon. Wea. Rev., 97, 163-172, https://doi.org/10.1175/ 1520-0493(1969)097<0163:ATFTEP>2.3.CO;2.

Cai, W. J., and Coauthors, 2014: Increasing frequency of extreme El Niño events due to greenhouse warming. Nat. Climate Change, 4, 111-116, https://doi.org/10.1038/nclimate2100.

, and Coauthors, 2019: Pantropical climate interactions. Science, 363, eaav4236, https://doi.org/10.1126/science.aav4236.

Capotondi, A., and Coauthors, 2015: Understanding ENSO diversity. Bull. Amer. Meteor. Soc., 96, 921-938, https://doi.org/ 10.1175/BAMS-D-13-00117.1.

Chang, P., and S. G. Philander, 1994: A coupled ocean-atmosphere instability of relevance to the seasonal cycle. J. Atmos. Sci., 51, 3627-3648, https://doi.org/10.1175/1520-0469(1994)051<3627: $\mathrm{ACOIOR}>2.0 . \mathrm{CO} ; 2$.

Chen, D., and Coauthors, 2015: Strong influence of westerly wind bursts on El Niño diversity. Nat. Geosci., 8, 339-345, https:// doi.org/10.1038/ngeo2399.

Chiodi, A. M., and D. E. Harrison, 2013: El Niño impacts on seasonal U.S. atmospheric circulation, temperature, and precip- itation anomalies: The OLR-event perspective. J. Climate, 26, 822-837, https://doi.org/10.1175/JCLI-D-12-00097.1.

Choi, J., S.-I. An, J.-S. Kug, and S.-W. Yeh, 2011: The role of mean state on changes in El Niño's flavor. Climate Dyn., 37, 12051215, https://doi.org/10.1007/s00382-010-0912-1.

Clarke, A. J., 2008: An Introduction to the Dynamics of El Niño and the Southern Oscillation. Academic Press, 324 pp.

Dee, D. P., and Coauthors, 2011: The ERA-Interim reanalysis: Configuration and performance of the data assimilation system. Quart. J. Roy. Meteor. Soc., 137, 553-597, https://doi.org/ 10.1002/qj.828.

Dewitte, B., and K. Takahashi, 2019: Diversity of moderate El Niño events evolution: Role of air-sea interactions in the eastern tropical Pacific. Climate Dyn., 52, 7455-7476, https:// doi.org/10.1007/s00382-017-4051-9.

Fedorov, A. V., S. Hu, M. Lengaigne, and E. Guilyardi, 2015: The impact of westerly wind bursts and ocean initial state on the development, and diversity of El Niño events. Climate Dyn., 44, 1381-1401, https://doi.org/10.1007/s00382014-2126-4.

Forget, G., J.-M. Campin, P. Heimbach, C. N. Hill, R. M. Ponte, and C. Wunsch, 2015: ECCO version 4: An integrated framework for non-linear inverse modeling and global ocean state estimation. Geosci. Model Dev., 8, 3071-3104, https:// doi.org/10.5194/gmd-8-3071-2015.

Fukumori, I., O. Wang, I. Fenty, G. Forget, P. Heimbach, and R. M. Ponte, 2017: ECCO version 4 release 3. MIT DSpace Rep., 10 pp., http://hdl.handle.net/1721.1/110380.

Ham, Y. G., J.-S. Kug, J.-Y. Park, and F.-F. Jin, 2013: Sea surface temperature in the north tropical Atlantic as a trigger for El Niño/Southern Oscillation events. Nat. Geosci., 6, 112-116, https://doi.org/10.1038/ngeo1686.

Hu, S., and A. V. Fedorov, 2017: The extreme El Niño of 20152016: The role of westerly and easterly wind bursts, and preconditioning by the failed 2014 event. Climate Dyn., 52, 73397357, https://doi.org/10.1007/s00382-017-3531-2.

, and - 2018: Cross-equatorial winds control El Niño diversity and change. Nat. Climate Change, 8, 798-802, https:// doi.org/10.1038/s41558-018-0248-0.

,-- M. Lengaigne, and E. Guilyardi, 2014: The impact of westerly wind bursts on the diversity and predictability of El Niño events: An ocean energetics perspective. Geophys. Res. Lett., 41, 4654-4663, https://doi.org/10.1002/2014GL059573.

Johnson, N. C., and Y. Kosaka, 2016: The impact of eastern equatorial Pacific convection on the diversity of boreal winter El Niño teleconnection patterns. Climate Dyn., 47, 3737-3765, https://doi.org/10.1007/s00382-016-3039-1.

Kang, I.-S., S.-I. An, and F.-F. Jin, 2001: A systematic approximation of the SST anomaly equation for ENSO. J. Meteor. Soc. Japan, 79, 1-10, https://doi.org/10.2151/jmsj.79.1.

Kao, H. Y., and J. Y. Yu, 2009: Contrasting eastern-Pacific and central-Pacific types of ENSO. J. Climate, 22, 615-632, https:// doi.org/10.1175/2008JCLI2309.1.

Kug, J. S., F. F. Jin, and S. I. An, 2009: Two types of El Niño events: Cold tongue El Niño and warm pool El Niño. J. Climate, 22, 1499-1515, https://doi.org/10.1175/2008JCLI2624.1.

Lengaigne, M., and G. A. Vecchi, 2010: Contrasting the termination of moderate and extreme El Niño events in coupled general circulation models. Climate Dyn., 35, 299-313, https:// doi.org/10.1007/s00382-009-0562-3.

Lian, T., D. Chen, Y. Tang, and Q. Wu, 2014: Effects of westerly wind bursts on El Niño: A new perspective. Geophys. Res. Lett., 41, 3522-3527, https://doi.org/10.1002/2014GL059989. 
Ma, J., S.-P. Xie, and H. Xu, 2017: Contributions of the North Pacific meridional mode to ensemble spread of ENSO prediction. J. Climate, 30, 9167-9181, https://doi.org/10.1175/JCLI-D-17-0182.1.

Marshall, J., A. Adcroft, C. Hill, L. Perelman, and C. Heisey, 1997: A finite volume, incompressible Navier-Stokes model for studies of the ocean on parallel computers. J. Geophys. Res., 102, 5753-5766, https://doi.org/10.1029/96JC02775.

Masunaga, H., and C. D. Kummerow, 2006: Observations of tropical precipitating clouds ranging from shallow to deep convective systems. Geophys. Res. Lett., 33, L16805, https:// doi.org/10.1029/2006GL026547.

McCreary, J. P., Jr., and D. L. Anderson, 1984: A simple model of El Niño and the Southern Oscillation. Mon. Wea. Rev., 112, 934-946, https://doi.org/10.1175/1520-0493(1984)112<0934: ASMOEN $>2.0 . \mathrm{CO} ; 2$.

McPhaden, M. J., 1999: Genesis and evolution of the 1997-98 El Niño. Science, 283, 950-954, https://doi.org/10.1126/ science.283.5404.950.

- 2004: Evolution of the 2002/03 El Niño. Bull. Amer. Meteor. Soc., 85, 677-695, https://doi.org/10.1175/BAMS-85-5-677.

, T. Lee, and D. McClurg, 2011: El Niño and its relationship to changing background conditions in the tropical Pacific Ocean. Geophys. Res. Lett., 38, L15709, https://doi.org/10.1029/ 2011 GL048275.

Neale, R. B., and Coauthors, 2012: Description of the NCAR Community Atmosphere Model (CAM 5.0). NCAR Tech. Note NCAR/TN-486+STR, 274 pp., www.cesm.ucar.edu/ models/cesm1.0/cam/docs/description/cam5_desc.pdf.

Ogata, T., S. P. Xie, A. Wittenberg, and D. Z. Sun, 2013: Interdecadal amplitude modulation of El Niño-Southern Oscillation and its impact on tropical Pacific decadal variability. J. Climate, 26, 7280-7297, https://doi.org/10.1175/ JCLI-D-12-00415.1.

Okumura, Y. M., 2019: ENSO diversity from an atmospheric perspective. Curr. Climate Change Rep., 5, 245-257, https:// doi.org/10.1007/s40641-019-00138-7.

— T. Sun, and X. Wu, 2017: Asymmetric modulation of El Niño and La Niña and the linkage to tropical Pacific decadal variability. J. Climate, 30, 4705-4733, https://doi.org/10.1175/ JCLI-D-16-0680.1.

Paek, H., J. Y. Yu, and C. Qian, 2017: Why were the 2015/2016 and 1997/1998 extreme El Niños different? Geophys. Res. Lett., 44, 1848-1856, https://doi.org/10.1002/2016g1071515.

Paulson, C. A., and J. J. Simpson, 1977: Irradiance measurements in the upper ocean. J. Phys. Oceanogr., 7, 952-956, https://doi.org/ 10.1175/1520-0485(1977)007<0952:IMITUO>2.0.CO;2.

Peng, Q., S.-P. Xie, D. Wang, X.-T. Zheng, and H. Zhang, 2019: Coupled ocean-atmosphere dynamics of the 2017 extreme coastal El Niño. Nat. Commun., 10, 298, https://doi.org/10.1038/ s41467-018-08258-8.

Philander, S. G., 1990: El Niño, La Niña, and the Southern Oscillation. International Geophysics Series, Vol. 46, Academic Press, 293 pp.

— equatorial winds (with application to coastal upwelling in low latitudes). Tellus, 33, 201-210, https://doi.org/10.3402/ tellusa.v33i2.10708.

Reynolds, R. W., N. A. Rayner, T. M. Smith, D. C. Stokes, and W. Q. Wang, 2002: An improved in situ and satellite SST analysis for climate. J. Climate, 15, 1609-1625, https://doi.org/ 10.1175/1520-0442(2002)015<1609:AIISAS>2.0.CO;2.

Sarachik, E. S., and M. A. Cane, 2010: The El Niño-Southern Oscillation Phenomenon. Cambridge University Press, $384 \mathrm{pp}$.

Siler, N., Y. Kosaka, S.-P. Xie, and X. Li, 2017: Tropical ocean contributions to California's surprisingly dry El Niño of 2015/16. J. Climate, 30, 10 067-10 079, https://doi.org/10.1175/JCLI-D-17-0177.1.

Takahashi, K., A. Montecinos, K. Goubanova, and B. Dewitte, 2011: ENSO regimes: Reinterpreting the canonical and Modoki El Niño. Geophys. Res. Lett., 38, L10704, https:// doi.org/10.1029/2011GL047364.

Timmermann, A., and Coauthors, 2018: El Niño-Southern Oscillation complexity. Nature, 559, 535-545, https://doi.org/ 10.1038/s41586-018-0252-6.

Vecchi, G. A., 2006: The termination of the 1997-98 El Niño. Part II: Mechanisms of atmospheric change. J. Climate, 19, 26472664, https://doi.org/10.1175/JCLI3780.1.

— , and D. E. Harrison, 2006: The termination of the 1997-98 El Niño. Part I: Mechanisms of oceanic change. J. Climate, 19 2633-2646, https://doi.org/10.1175/JCLI3776.1.

Wyrtki, K., 1975: El Niño-The dynamic response of the equatorial Pacific Ocean to atmospheric forcing. J. Phys. Oceanogr., 5, 572-584, https://doi.org/10.1175/1520-0485(1975)005<0572: ENTDRO $>2.0 . \mathrm{CO} ; 2$.

Xie, P., and P. A. Arkin, 1997: Global precipitation: A 17-year monthly analysis based on gauge observations, satellite estimates, and numerical model outputs. Bull. Amer. Meteor. Soc., 78, 2539-2558, https://doi.org/10.1175/1520-0477(1997) 078<2539:GPAYMA $>2.0 . \mathrm{CO} ; 2$.

Xie, S. P., and S. G. H. Philander, 1994: A coupled oceanatmosphere model of relevance to the ITCZ in the eastern Pacific. Tellus, 46A, 340-350, https://doi.org/10.3402/tellusa. v46i4.15484.

—, Q. Peng, Y. Kamae, X. T. Zheng, H. Tokinaga, and D. Wang, 2018: Eastern Pacific ITCZ dipole and ENSO diversity. J. Climate, 31, 4449-4462, https://doi.org/10.1175/JCLI-D17-0905.1.

Yeh, S. W., J.-S. Kug, B. Dewitte, M.-H. Kwon, B. P. Kirtman, and F.-F. Jin, 2009: El Niño in a changing climate. Nature, 461, 511-514, https://doi.org/10.1038/nature08316.

Yu, H. Y., and M. H. Zhang, 2018: Explaining the year-to-year variability of the eastern Pacific intertropical convergence zone in the boreal spring. J. Geophys. Res. Atmos., 123, 3847 3856, https://doi.org/10.1002/2017JD028156.

Yu, J. Y., H. Y. Kao, and T. Lee, 2010: Subtropics-related interannual sea surface temperature variability in the central equatorial Pacific. J. Climate, 23, 2869-2884, https://doi.org/ 10.1175/2010JCLI3171.1.

Zebiak, S., and M. Cane, 1987: A model El Niño-Southern Oscillation. Mon. Wea. Rev., 115, 2262-2278, https://doi.org/ 10.1175/1520-0493(1987)115<2262:AMENO>2.0.CO;2.

Zhang, X., and M. J. McPhaden, 2006: Wind stress variations and interannual sea surface temperature anomalies in the eastern equatorial Pacific. J. Climate, 19, 226-241, https://doi.org/ 10.1175/JCLI3618.1.

$\longrightarrow$, and - 2008: Eastern equatorial Pacific forcing of ENSO sea surface temperature anomalies. J. Climate, 21, 6070-6079, https://doi.org/10.1175/2008JCLI2422.1. 